RESEARCH

\title{
ASSESSMENT OF THE BURDEN AMONG FAMILY CAREGIVERS OF PATIENTS WITH ALZHEIMER'S DISEASE
}

Turkish Journal of Geriatrics DOI: 10.31086/tjgeri.2021.225 2021; 24(2): 287-295

- Rukiye Pınar BÖLÜKTAŞ

CORRESPONDANCE

${ }^{1}$ Rukiye Pınar BÖLÜKTAŞ

Istanbul Sabahattin Zaim University, Faculty of Health Sciences, Department of Nursing, Istanbul, Turkey

\section{Phone: +905376590010 \\ e-mail: rukiye.boluktas@izu.edu.tr}

Received: Dec 17, 2020

Accepted: Apr 24, 2021

${ }^{1}$ Istanbul Sabahattin Zaim University, Faculty of Health Sciences, Department of Nursing, Istanbul, Turkey

\section{Abstract}

Introduction: The objective of this study was to examine the caregiving burden and identify the predictors of burden among family caregivers of patients with Alzheimer's disease.

Materials and Method: The sample consisted of 154 family caregivers of community-dwelling Alzheimer patients. Zarit Burden Inventory was used to measure caregiver burden. Depending on the total score, the level of burden is classified as absent to little burden ( 0 to $\leq 20)$, mild to moderate burden (21 to 40 ), moderate to severe burden (41 to 60$)$, and very severe burden ( $\geq 61)$. The cutoff point for the clinical depression was taken as 24.

Results: The caregivers were mainly women (78.6\%), the patient's daughters (56.5\%), living with the patient (79.1\%), and they were not receiving any support from other family members for patient care (54.5\%). The average time spent on caregiving tasks was 4.8 hours a day. The mean Zarit Burden Inventory score was 22.4. The burden scores of $39.6 \%$ of the caregivers were significant for clinical depression. The most pronounced predictors of higher burden were the absence of someone supporting the care, social isolation, the length of time spent daily for caregiving, and the patient's age, comorbidities, and functional impairment in daily activities. Receiving psychological counselling was a protective factor against the development of burden.

Conclusion: The results suggest that burden is high among the caregivers of patients with Alzheimer's disease. Strategies should be developed to support family members in countries such as Turkey, where the care is undertaken by informal caregivers.

Key Words: Alzheimer Disease; Cost of Illness; Family Caregivers; Patient Care; Long-term Care 


\section{INTRODUCTION}

There are approximately 50 million people with dementia in the world today, with around 10 million new cases being diagnosed every year. The number of people with dementia is predicted to exceed 131 million by 2050 (1). Although it is not a natural part of the aging process, dementia primarily affects older people and about $7 \%$ of the individuals over the age of 65 have dementia. The most common type of dementia is Alzheimer's disease (AD), which accounts for 60 to $70 \%$ of the cases (2).

The care needs of people with dementia are relatively complex (3). It has been shown that family members generally care for individuals with dementia for 10 or more years prior to either the institutionalization or the death of the patient $(1,3)$. Family caregivers are obliged to meet all of the physical, psychological, and social care needs of these patients. Caregivers are compelled to adjust their lives according to the patients' needs, with the resulting shortage of time for their own lives, along with increased social isolation and financial difficulties, leading to caregiving burden (CB) (3).

Currently, more than 600,000 people suffer from dementia in Turkey and 400,000 of them have AD (4). Individuals with $A D$ frequently live with their family, and institutionalization is extremely low (4). The lifespan in Turkey has increased, and the percentage of people with ages $>65$ years increased from 8\% in 2014 to $9.1 \%$ in 2019. The percentage of the elderly population is projected to increase to $10.2 \%$ in 2023 , to $12.9 \%$ in 2030 , and to $16.3 \%$ in 2040. The number of elderly people who died from AD increased from 10,236 in 2014 (3.9\%) to 13,767 (4.6\%) in 2018 (5).

In examining these figures, it can be predicted that the number of cases of $A D$ will increase in parallel with the increase in the elderly population. Consequently, in the future, we will need more family caregivers and more people will have CB as well. To our knowledge, there have only been two studies on $\mathrm{CB}$ among the family caregivers of patients with dementia in Turkey (6-7). More research with a larger sample is still needed. Moreover, little is known about some of the independent predictors of CB. Considering the dramatically increasing number of patients with Alzheimer in Turkey, assessing the family's CB and independent predictors of CB will guide us in developing, implementing, and assessment strategies to support family members. In this study, we aimed to examine the CB and the affecting factors among the family members of patients with $A D$ in Turkey.

\section{Study Questions}

- What is the level of CB of family members caring for Alzheimer's patients?

- What are the factors affecting CB in family members caring for Alzheimer's patients?

\section{MATERIALS AND METHOD}

\section{Research design}

A cross-sectional research design was used in this study.

\section{Participants and setting}

The study was conducted between May 2 and November 29, 2019 in Istanbul, Turkey in the day nursing home of the Turkish Alzheimer Association. Serving since 2011, the day nursing home provides Alzheimer's patients and family caregivers with free education, social support and psychological support on various subjects in cooperation with specialist physicians, nurses, social workers, psychologists and volunteers. The family caregivers who came to the day nursing home between the study dates and met the inclusion criteria were explained the purpose of the study and invited to take part. The caregivers were included in the study if they were 18 years of age or over, had been performing the care of the patient for at least 6 months, and agreed to participate in the study. The study participants included 154 primary informal family caregivers of community-dwelling patients with AD. Only one 
caregiver per patient was included in the study.

\section{Measures}

The data were collected using the Information Sheet and Zarit Burden Interview (ZBI).

The Information Sheet was prepared by the researchers using the relevant literature and includes questions for caregivers and patients in two parts. The first part includes questions about socio-demographic variables such as age, gender, and marital status of the caregivers, as well as health status, providing care and difficulties in providing care. The second part includes questions about the patients' age, gender, years since diagnosis, health status, and ability to perform daily life activities (DLAs) including walking and moving around, eating and drinking, toileting, dressing, and body hygiene as well as presence of any speaking and sleep problems.

ZBI was used to measure caregiver burden. It includes 22 items scored over a 5-point Likert-type scale ranging from 0 , "never" to 4, "almost always". Responses to the items in the ZBI are added together to calculate a total burden score ranging from 0 to 88. Higher scores indicate greater burden. Depending on the total score, the level of burden is classified as absent to little burden ( 0 to $\leq 20)$, mild to moderate burden ( 21 to 40 ), moderate to severe burden ( 41 to 60$)$, and very severe burden ( $\geq 61$ ). The cutoff point for the ZBI was reported as 24 , meaning that individuals with more than 24 points are at risk for clinical depression (8). The internal consistency for the original ZBI was 0.89 (9). In the current study, Cronbach's alpha value of the ZBI was 0.95 .

\section{Data collection}

Data collection tools were distributed to family caregivers who came to the day nursing home for various activities and they were asked to complete the forms by themselves. The ability of the patient to perform daily life activities (DLAs) was also evaluated by family caregivers. The patients were classified as independent if they were able to perform
DLAs with no assistance, semi-dependent if they were able to DLAs with assistance or supervision, and dependent if they were entirely dependent on others to meet their basic needs. The family caregivers answered two questions, i.e. "Does your patient has speech problem?" and "does your patient has sleep problem" as yes or no. Each participant took about 20 minutes to fill out the data collection tools.

Before collecting the data, ethical approval was obtained from the University Ethics Committee in accordance with the Helsinki Declaration (2019/27). Written informed consent was obtained from each participant.

\section{Statistical analyses}

Normality tests (histogram, skewness, kurtosis, Shapiro-Wilk) were performed to determine whether the ZBI mean score was suitable for normal distribution. Pearson's correlation coefficients were calculated to examine the relationships between two continuous variables. Independent unpaired t-tests were used for two-group comparisons of continuous variables. The one-way ANOVA was used to compare the scores for three-group comparisons of the continuous variables. Homogeneity was examined using the Levene test. Data was presented as numbers and mean \pm standard deviations (SD), where appropriate. The effects of the independent variables on the $\mathrm{CB}$ were examined using linear regression analysis.

The significance level was taken as $P<0.05$. Data analyses were conducted using SPSS, version 22.0 (IBM SPSS Corp.; Armonk, NY, USA).

\section{RESULTS}

\section{The characteristics of the caregivers}

The descriptive characteristics of the family caregivers are provided in Table 1. The majority of the caregivers were women (78.6\%). They had a mean age of 45.1 years; $69.5 \%$ were married, $66.2 \%$ had children, $59.7 \%$ were unemployed, and $46.1 \%$ were 
Table 1. Characteristics of the caregivers $(N=154)$

\begin{tabular}{|c|c|}
\hline Characteristics & Number (\%) \\
\hline Gender (Female) & $121(78.6)$ \\
\hline Age (Mean \pm SD years) (Min-max) & $45.1 \pm 13.30$ (Min-max: 23-77) \\
\hline Marital status (Married) & $107(69.5)$ \\
\hline Having children (Yes) & $102(66.2)$ \\
\hline $\begin{array}{l}\text { Education } \\
\text { Primary school } \\
\text { Secondary school / High school } \\
\text { University }\end{array}$ & $\begin{array}{l}37(24.0) \\
46(29.9) \\
71(46.1)\end{array}$ \\
\hline Employment (unemployed) & $92(59.7)$ \\
\hline $\begin{array}{l}\text { Financial status } \\
\text { Poor / Moderate }\end{array}$ & $36(23.4) / 118(76.6)$ \\
\hline $\begin{array}{l}\text { Relationship to the patient } \\
\text { Daughter / Spouse } \\
\text { Daughter in law / Second degree relatives }\end{array}$ & $\begin{array}{l}87(56.5) / 11(7.1) \\
34(22.1) / 22(14.3)\end{array}$ \\
\hline Living with patient (Yes) & $122(79.1)$ \\
\hline Length of time spent on caregiving tasks during the day (Mean \pm SD) (Min-max) & 4.83 $\pm 2.2($ Min-max: $1-11)$ \\
\hline Presence of someone else to help patient care (No) & $84(54.5)$ \\
\hline Having a chronic disease (Yes) & $61(39.6)$ \\
\hline \multicolumn{2}{|l|}{ Problems related to caregiving reported by caregivers } \\
\hline Physical and/or psychological health problems (Yes) & $132(64.7)$ \\
\hline Feeling exhausted (Yes) & $76(49.4)$ \\
\hline $\begin{array}{l}\text { Economic burden } \\
\text { Always / Sometimes / Never }\end{array}$ & $17(11.0) / 86(55.8) / 51(33.1)$ \\
\hline $\begin{array}{l}\text { Negative impact on social life (being unable to spend time in personal social life etc.) } \\
\text { Always / Sometimes / Never }\end{array}$ & $39(25.3) / 60(39.0) / 55(35.7)$ \\
\hline $\begin{array}{l}\text { Negative impact on family relationship } \\
\text { Always / Sometimes / Never }\end{array}$ & $59(38.3) / 53(34.4) / 42(27.3)$ \\
\hline $\begin{array}{l}\text { Feeling insufficient in caregiving tasks } \\
\text { Always / Sometimes / Never }\end{array}$ & 27 (17.5) / 78 (50.6) / 49 (31.8) \\
\hline Getting psychological support related to caregiving (Yes) & $41(26.6)$ \\
\hline Attending an education programme on patient care with AD (Yes) & $122(79.2)$ \\
\hline
\end{tabular}


university graduates. Most of them described their financial status as moderate (76.6\%). The majority of the caregivers (56.5\%) were the daughters of the patient and they lived with them (79.1\%), and 54.5\% did not receive any support from other family members for patient care. The average time spent on caregiving tasks was 4.8 hours a day.

A significant proportion of the participants stated that providing care caused some physical and mental problems (64.7\%), tiredness and exhaustion (49.4\%), and economic burden (always, 25.3\%; sometimes, $39 \%$ ). In addition, $39.6 \%$ had a chronic disease. The caregivers also stated that providing care affected both their social life (always, 25.3\%; sometimes, 39\%) and their family relationships negatively (always, 38.3\%; sometimes, 34.4\%). Some caregivers stated that they felt inadequate in caregiving tasks (always, 17.5\%; sometimes, 50.6\%); $26.6 \%$ of them received psychological support to solve problems related to caregiving, and most of them (79.2\%) attended an education program on the care of a patient with $A D$.

\section{The characteristics of the patients}

The characteristics of the patients are shown in Table 2. The mean age of the patients was 76 years, $50.6 \%$ were male, the mean time since the diagnosis of $A D$ was 4.8 years, and $92.2 \%$ of the patients had a comorbidity. When the ability to perform daily life activities was examined, the percentage of the patients who could walk/move around, eat and drink, manage toilet needs, dress and maintain body hygiene independently was found to be $53.9,55.2$, 53.9, 41.6, and 37\%, respectively. The remaining patients were fully- or semi-dependent in varying degrees on others in performing these activities. Approximately 4 (39\%) of 10 patients had speaking difficulties, and 7 (71.4\%) had sleep problems.

Table 2. Characteristics of the patients $(N=154)$

\begin{tabular}{|c|c|}
\hline Characteristics & Number (\%) \\
\hline Gender (Male) & $78(50.6)$ \\
\hline Age (Mean \pm SD years) (Min-max) & $75.92 \pm 9.50$ (Min-max: 55-91) \\
\hline Time since diagnosis (Mean \pm SD years) (Min-max) & $4.81 \pm 2.3$ (Min-max: 1-15) \\
\hline Having a chronic disease (Yes) & $142(92.2)$ \\
\hline \multicolumn{2}{|l|}{ Ability to perform daily life activities } \\
\hline $\begin{array}{l}\text { Walking / moving around } \\
\text { Independent / Semi-dependent / Dependent }\end{array}$ & $83(53.9) / 40(26.0) / 31(20.1)$ \\
\hline $\begin{array}{l}\text { Eating/drinking } \\
\text { Independent / Semi-dependent / Dependent }\end{array}$ & 85 (55.2) / 52 (33.8) / 17 (11.0) \\
\hline $\begin{array}{l}\text { Toileting } \\
\text { Independent / Semi-dependent / Dependent }\end{array}$ & $83(53.9)$ / 40 (26.0) / 31 (20.1) \\
\hline $\begin{array}{l}\text { Dressing } \\
\text { Independent / Semi-dependent / Dependent }\end{array}$ & $64(41.6) / 60(39.0) / 30(19.5)$ \\
\hline $\begin{array}{l}\text { Body hygiene } \\
\text { Independent / Semi-dependent / Dependent }\end{array}$ & $57(37.0) / 38(24.7) / 59(38.3)$ \\
\hline Speaking problems (Yes) & $60(39.0)$ \\
\hline Sleep problems (Yes) & $110(71.4)$ \\
\hline
\end{tabular}




\section{Caregiving burden and related factors}

The mean ZBI score was 22.4, and $27.3 \%$ of the caregivers reported mild to moderate burden (ZBI $21-40), 18.8 \%$ reported moderate to severe burden (ZBI 41-60), and 53.9\% reported absent to little burden $(Z B \mid \leq 20)$. According to the cutoff point, $39.6 \%$ of the caregivers had CB scores that were clinically significant.

\section{Factors affecting the caregiving burden}

In the initial analysis, it was determined that some of the variables related to the caregiver and the patient affected CB.

These variables were examined using a multiple regression analysis. The results of this analysis are presented in Table 3. As seen in the table, the effect of the independent variables included in the analysis on the CB was determined to be $81.3 \%$. According to the results of the F-test, the linear relationship between the $\mathrm{CB}$ and the set of independent variables belonging to the caregivers and the patients was found to be statistically significant $(F=62.33, P<0.001)$. When the partial regression coefficients (b) determining the effect of each independent variable were examined, it was seen that the contribution of all of the independent variables to the change in the $\mathrm{CB}$ mean score was statistically significant, except for living with the patient.

\section{DISCUSSION}

Studies have shown that a significant number of factors affect CB. In some studies, the functional impairment in daily living activities was reported to pose a higher risk for CB (10-14). In others, being a woman, being a partner, not receiving support from family members, and lack of knowledge on dementia were predictors of $\mathrm{CB}$. In comparison, receiving

Table 3. Results of regression analysis $(N=154)$

\begin{tabular}{|c|c|c|c|c|}
\hline & \multicolumn{4}{|c|}{ ZBI } \\
\hline & B & Beta & $\mathrm{t}$ & $\mathbf{P}$ \\
\hline \multicolumn{5}{|l|}{ Caregivers' characteristics } \\
\hline Living with the patient & -1.180 & -0.031 & 0.73 & 0.468 \\
\hline Absence of someone else supporting care & -4.857 & -0.159 & 4.12 & $0.000 * \star \star$ \\
\hline Negative impact of caregiving on social life & -3.472 & -0.181 & 4.063 & $0.000^{\star \star \star}$ \\
\hline Receiving psychological counselling related to caregiving & 6.373 & 0.185 & 4.420 & $0.000^{\star * *}$ \\
\hline Length of the time spent on caregiving tasks during the day & -3.950 & -0.576 & 12.25 & $0.000^{\star \star \star}$ \\
\hline \multicolumn{5}{|l|}{ Patients' characteristics } \\
\hline Age & -0.154 & -0.096 & -2.546 & $0.012^{\star}$ \\
\hline Comorbidity & -7.844 & -0.138 & 3.146 & $0.002^{\star \star}$ \\
\hline Walking / moving around & -2.590 & -0.145 & 3.074 & $0.003^{* *}$ \\
\hline Toileting & -2.999 & -0.168 & 3.549 & $0.001^{* *}$ \\
\hline Body hygiene & -3.768 & -0.192 & -3.664 & $0.000^{\star * \star}$ \\
\hline$R=0.902, R^{2}=0.813, F=62.33, P=0.000 * \star \star$ & & & & \\
\hline
\end{tabular}

${ }^{\star} \mathrm{P}<0.05 ;{ }^{* \star P}<0.01 ;{ }^{* \star *} \mathrm{P}<0.001$ 
support from informal sources, such as friends and neighbors, and having adequate knowledge regarding dementia were protective factors (15-17).

We found that approximately $40 \%$ of the caregivers perceived significant $C B$ at the clinical level. Explaining $81.3 \%$ of the total variance, the most important predictors of CB were the absence of someone else supporting the care, limitations on social life, receiving no psychological counselling, the length of time spent daily for caregiving, caring for a relatively younger patient, the patient's comorbidities, and the patient's functional impairment in daily activities_including walking/-moving around, toileting, and body hygiene. These findings indicate that the CB shows both the influence of some variables and the cumulative effect of caregiving work on the family member.

In the current study, patients' dependence or semi-dependence in walking and moving around, toileting, and body hygiene activities were important predictors of CB. In addition, the absence of a second person to support the care had a negative impact on the CB. Since walking/moving around, toileting, and maintaining body hygiene are both time-consuming and tiring activities that require significant strength and attention, it was anticipated that these variables would be predictive of CB. It is not difficult to predict that the absence of a second person to help support the care will be a predictor of CB. Previous studies have shown that functional impairment, dependence in daily life activities (1115), and the absence of a second caregiver (15) all increase the $\mathrm{CB}$. Our results are consistent with the literature.

Different studies have shown contradictory results on the impact on the burden of being a shortor a long-term caregiver. Some studies suggested that the CB increases (18-20), and one reported that the CB decreases over time (21). In our study, being a short- or a long-term caregiver did not have an influence on the ZBI scores although the burden increased as the time allocated for caring increased during the day. We feel that the time that the caregiver actively spends on caregiving tasks affects the $C B$, rather than the days, months, and years spent with the patient.

In our study, a negative correlation was found between the patient's age and the CB, and a relatively younger age was an independent predictor of higher CB. Although previous investigations have shown similar results $(12,18)$, a positive correlation was found between the $C B$ and the patient's age in some studies (7-8). The possible explanation for our finding is as follows: The current life experiences and the life expectancies of family members who provide care for young patients are different. Since the care demands of the young patients are higher, it might be possible that the caregivers of younger patients perceive a higher burden. As the patients get older, hospital admissions due to comorbidities increase, which may slightly reduce the burden of family members (17). Nevertheless, future research needs to determine the relationship between the patient's age and the CB.

Most patients with dementia lose their ability to understand and communicate and over time, they become almost dependent on others to maintain life (22). As a result, the caregivers of $A D$ patients provide fulltime caregiving support to these patients. Both the physical burden of direct caregiving and the consequent restrictions on social life cause the caregiving individual to perceive more burden (22). In the current study, $64.3 \%$ of the caregivers reported that providing care negatively affected their social life. Consistent with the literature, the negative impact on social life appears to be an important predictive variable for increased CB.

It has been reported that psychosocial well-being is associated with CB (23) and that psychosocial interventions will reduce the $\mathrm{CB}$ and improve the quality of life for the caregiver (24). In the current study, the ZBI mean scores were lower among 
caregivers who received psychological counselling (26.6\%). Our results are consistent with the literature.

The present study has some limitations to be considered. The main ones include the convenience sampling of the family caregivers and the limited data collected on the participants. The data did not contain some important information such as the neuropsychiatric symptoms of the patients, the severity of the dementia, or the coping strategies of the caregivers.

Previous research has found that the levels of burden may be moderated by the patient's symptoms and the severity of the dementia $(12,14)$. Previous research has also shown that positive feelings are associated with a decreased burden level (25). The current study was also limited by the fact that it did not specifically assess the positive effects of caregiving (such as feeling useful or the increased closeness with the patient) that are not indexed in the ZBI. Therefore, the results of the present study should be interpreted cautiously.

\section{REFERENCES}

1. Alzheimer's Disease International-London. World Alzheimer Report 2015. [Internet]. The Global impact of dementia: An analysis of prevalence, incidence, cost and trends. Available from: https://www.alz. co.uk/research/WorldAlzheimerReport2015-sheet. pdf. Accessed: 18.06.2020.

2. World Health Organization. Dementia 2019. [Internet]. Available from: https://www.who.int/newsroom/fact-sheets/detail/dementia. Accessed: 18.06.2020.

3. Sutcliffe C, Giebel C, Bleijlevens M, et al. Caring for a person with dementia on the margins of longterm care: a perspective on burden from 8 European countries. J Am Med Dir Assoc 2017; 18 (11): 967-73. e1. (PMID: 28733181)

4. Turkish Alzheimer Society. Alzheimer's disease. [Internet]. Available from: https://www.alzheimer-europe. org/Alzheimer-Europe/Who-we-are/Our-members/ Tuerkiye-Alzheimer-Dernegi. Accessed: 03.07.2020.

\section{CONCLUSION}

In conclusion, despite the limitations, our data confirms that the CB was very common among our sample, and the most pronounced predictors for burden were the absence of someone else supporting the care, social isolation, the length of time spent daily for caregiving, and the patient's age, comorbidities, and functional impairment in daily activities. Receiving psychological counselling was a protective factor against the development of burden.

We believe that it may be possible to minimize the burden by providing occasional care support from formal or volunteer caregivers, thereby reducing the length of time spent per day in caregiving and decreasing the negative impact of caregiving on the caregiver's life. Psychological counselling should be provided as much as possible to reduce and prevent the CB. Caregivers of patients with advanced age, with comorbidities, and with functional impairments should be especially supported.

\section{Conflict of Interest}

No conflict of interest to disclosure.

5. Turkish Statistical Institute (TurkStat). Elderly with statistics 2019. [Internet]. Available from: https:// data.tuik.gov.tr/Bulten/Index? $p=$ Istatistiklerle-Yaslilar-2019-33712. Accessed: 07.12.2020. (in Turkish)

6. Kucukguclu O, Soylemez BA, Yener G, Barutcu CD, Akyol MA. Examining factors affecting caregiver burden: a comparison of frontotemporal dementia and Alzheimer's disease. Am J Alzheimers Dis Other Demen 2017; 32 (4): 200-206. (PMID: 28403621)

7. Tulek Z, Baykal D, Erturk S, Bilgic B, Hanagasi H, Gurvit $\mathrm{IH}$. Caregiver burden, quality of life and related factors in family caregivers of dementia patients in Turkey. Issues Ment Health Nurs 2020; 41 (8): 741-49. (PMID: 32286096)

8. Schreiner AS, Morimoto T, Arai Y, Zarit S. Assessing family caregiver's mental health using a statistically derived cut-off score for the Zarit Burden Interview. Aging Ment Health 2006; 10 (2): 107-11. (PMID: 16517485) 
9. Zarit SH, Antony CR, Boutselis M. Interventions with caregivers of dementia patients: comparison of two approaches. Psychol Aging 1987; 2 (3): 225-32. (PMID: 3268213)

10. Cheng ST. Dementia caregiver burden: a research update and critical analysis. Curr Psychiatry Rep 2017; 19 (9): 64. (PMID: 28795386)

11. Feast A, Moniz-Cook E, Stoner C, Charlesworth G, Orrell M. A systematic review of the relationship between behavioral and psychological symptoms (BPSD) and caregiver well-being. Int Psychogeriatr 2016; 28 (11): 1761-74. (PMID: 27345942)

12. Ransmayr G, Hermann P, Sallinger K, et al. Caregiving and caregiver burden in dementia home care: results from the prospective dementia registry (PRODEM) of the Austrian Alzheimer Society. J Alzheimers Dis 2018; 63 (1): 103-14. (PMID: 29614643)

13. Ringer TJ, Hazzan AA, Kennedy CC, et al. Care recipients' physical frailty is independently associated with subjective burden in informal caregivers in the community setting: a cross-sectional study. BMC Geriatr 2016; 16 (1): 186. (PMID: 27855633)

14. Shuai L, Chonghui L, Zhihong S, et al. Caregiver burden and prevalence of depression, anxiety and sleep disturbances in Alzheimer's disease caregivers in China. J Clin Nurs 2017; 26 (9-10): 1291-1300. (PMID: 27681477)

15. Wang Z, Ma C, Han H, et al. Caregiver burden in Alzheimer's disease: moderation effects of social support and mediation effects of positive aspects of caregiving. Int J Geriatr Psychiatry 2018; 33(9): 11981206. (PMID: 29856091)

16. Zarit SH, Femia EE, Kim K, Whitlatch CJ. The structure of risk factors and outcomes for family caregivers: implications for assessment and treatment. Aging Ment Health 2010; 14 (2): 220-31. (PMID: 20336554)

17. Isik AT, Soysal P, Solmi M, Veronese N. Bidirectional relationship between caregiver burden and neuropsychiatric symptoms in patients with Alzheimer's disease: a narrative review. Int J Geriatr Psychiatry 2019; 34 (9): 1326-34. (PMID: 30198597)

18. Connors MH, Seeher K, Teixeira-Pinto A, Woodward M, Ames D, Brodaty H. Dementia and caregiver burden: a three-year longitudinal study. Int J Geriatr Psychiatry 2020; 35 (2): 250-58. (PMID: 31821606)

19. Park MH, Smith SC, Hendriks AAJ, Black N. Caregiver burden and quality of life 2 years after attendance at a memory clinic. Int J Geriatr Psychiatry 2019; 34 (5): 647-56. (PMID: 30730066)

20. Perales J, Turró-Garriga O, Gascón-Bayarri J, ReñéRamírez R, Conde-Sala JL. The longitudinal association between a discrepancy measure of anosognosia in patients with dementia, caregiver burden and depression. J Alzheimers Dis 2016; 53 (3): 1133-43. (PMID: 27258415)

21. Millenaar JK, de Vugt ME, Bakker C, et al. The impact of young onset dementia on informal caregivers compared with late onset dementia: results from the NeedYD study. Am J Geriatr Psychiatry 2016; 24 (6): 467-74. (PMID: 26560507)

22. USA Alzheimer's Association. Alzheimer's disease facts \& figures 2017. [Internet]. Available from: https://www.alz.org/alzheimers-dementia/facts-figures. Accessed: 29.06.2020.

23. Lethin C, Renom-Guiteras A, Zwakhalen S, et al. Psychological well-being over time among informal caregivers caring for persons with dementia living at home. Aging Ment Health 2017; 21 (11): 1138-46. (PMID: 27463390)

24. Dickinson C, Dow J, Gibson G, Hayes L, Robalino S, Robinson L. Psychosocial intervention for carers of people with dementia: what components are most effective and when? a systematic review of systematic reviews. Int Psychogeriatr 2017; 29 (1): 31-43. (PMID: 27666669)

25. Yu DSF, Cheng ST, Wang J. Unravelling positive aspects of caregiving in dementia: an integrative review of research literature. Int J Nurs Stud 2018; 79: 1-26. (PMID: 29128685) 